\title{
Swimming with the Shoal
}

\author{
Ann Childs ${ }^{1}$ (D)
}

Received: 7 April 2017/Accepted: 17 April 2017/Published online: 4 October 2017

(C) The Author(s) 2017. This article is an open access publication

\begin{abstract}
This article responds to Yuli Rahmawati and Peter Charles Taylor's piece and explores my role as a science teacher, science teacher educator and researcher in two contexts, Sierra Leone and Bhutan. In the first part of the article I reflect on my 3 years as a science teacher in Sierra Leone and demonstrate resonances with Yuli's accounts of culture shock and with her positioning of herself in a third space. I also reflect on the importance of colleagues in helping me reshape my identity as a science teacher in this new context. The second part of the article reflects on much shorter periods of time in Bhutan and my work as a teacher educator and researcher where, unlike Sierra Leone, it was not possible because of the short periods I worked there, to occupy a third space. I close by discussing how in Bhutan, but also Sierra Leone, collaboration with colleagues allowed me to contribute my own expertise, despite my lack of a deep understanding of the cultural context, in a way that was as valuable as possible. I liken this way of collaborative working in my professional life as 'swimming with the shoal'.
\end{abstract}

Keywords Science teacher identity · Collaboration · Distributed expertise

In this paper I want to respond in kind to Yuli and Peter's paper and I will do so by drawing on some professional experiences while working as a science teacher in Sierra Leone and as a teacher educator and researcher in Bhutan. These experiences both professionally and personally resonate with Yuli's account in some respects and I will try and unpick some of

Lead editor: M. Reiss.

This is a response to Rahamawati, Y., \& Taylor, P. C. (this issue). The fish becomes aware of the water in which it swims: Revealing the power of culture in shaping my teaching identity. Cultural Studies of Science Education. doi:10.1007/s11422-016-9801-1.

Ann Childs

ann.childs@education.ox.ac.uk

1 Department of Education, Oxford University, 15 Norham Gardens, Oxford OX2 6PY, UK 
the similarities and differences between my own experiences and Yuli's through this narrative.

\section{Sierra Leone}

I was born in London, an identical twin, within the sounds of the Bow Bells which makes me a so-called 'Cockney' but, as a family, we quickly moved to the suburbs of London and so my identity as a Cockney was somewhat diluted by this. Both my twin sister and I were the first in our family to go to University, she to study law and me to study chemistry at Birmingham University. I stayed to do my PhD in Chemistry there and then did a Post Graduate Certificate in Education (PGCE), the customary qualification for those intending to become teachers who already had a degree, at Oxford University where I took up my first appointment as a science teacher in a local state school.

After 4 years of teaching I applied to an organisation called Voluntary Services Overseas (VSO) and was placed as a chemistry teacher in a small rural school in the Northern Bombali region of Sierra Leone. Yuli and Peter's paper made me reflect again on this experience both professionally and personally. Initially, and my diary of the time certainly attests to this, I experienced all the negative characteristics of culture shock that are described in Yuli and Peter's paper. Personally, I was chronically homesick and professionally I felt like a beginning teacher all over again. I had gone to Sierra Leone as a relatively experienced science teacher of 4 years but it felt like none of this experience in any way prepared me for teaching in a school which was so different on so many fronts-the strong professional identity I had built up as a teacher in the UK was eroded significantly.

I was fortunate to have some very experienced colleagues in the school who supported this transition and their patience and understanding allowed me to learn what I needed to professionally in order to work more effectively as a science teacher. They also supported me personally - some of these people have remained friends to this day. In my professional life they supported me in learning how to teach students for whom English was a second, sometimes third, language to learn science using locally available resources; for example, I taught some biology and they gradually introduced me to the diverse flora and fauna of Sierra Leone. Personally, I joined the deputy head's family to eat and socialise and my colleagues and this family spoke to me only in Krio and so over the course of the first year I became reasonably fluent. This was an incredibly important transition as I could now communicate much more fluently with my colleagues and students and with people in the village.

Yuli says in her paper that "Even though I had been living in Australia for almost 6 years I continued to experience culture shock". This too resonates with my experience. In my village after living there for 3 years I rarely experienced culture shock. However when I visited friends in other districts of Sierra Leone culture shock did resurface, but in a much more positive sense, and this is because of the rich cultural differences between different parts of Sierra Leone.

Finally, Yuli talks about inhabiting a "third space' that results from the tensions between different cultures influencing my sense of cultural identity". I too, on reflection, seemed to occupy a third space and chose, like Yuli, not to 'merge' cultures. For example, I was never able to agree that the corporal punishment of pupils was acceptable although I better understood why teachers used it as a form of discipline. Although I felt I understood the culture within my village relatively well I never felt I could completely know everything because, in the relatively short time I was there, it was not possible fully to learn about or be truly part of the complex cultural milieu in which I was swimming. Sierra 
Leone has seven main cultural groups who speak different languages and I was in a village where there were two main ethnic groups: the Limba and Mandingo. I never learned these languages other than to be able to greet people and so I was still essentially a stranger, a knowledgeable stranger, but a stranger nonetheless. However, although initially the differences between my life and work in the UK and in Sierra Leone completely overwhelmed my sense of identity, after some time I realised a rather obvious point, namely that the people I lived and worked with had much the same hopes and aspirations for their children that any parent would have; the teachers, many from the village, wanted the students to do well and the students were the same as any teenagers I had taught- they subverted the school uniform, they had friendship issues and so on. Moreover, this experience, both consciously and unconsciously, shaped my interactions and understandings of the work I was later engaged in Oxford and in Bhutan.

\section{Bhutan: distributed expertise or middle way?}

In my work in Bhutan I was involved in a science curriculum review, a 'needs assessment', working in collaboration with colleagues at the then Curriculum and Professional Support Division (CAPSD) of the Ministry of Bhutan and with two colleagues from Oxford University Department of Education (OUDE). I had joined OUDE in 1995 after 11 years as a science teacher, three, as indicated above, in Sierra Leone. The needs assessment was intended to inform the development of a revised science curriculum framework. Although, to date, I have visited Bhutan eight times, each visit has been for no more than 3 weeks and so initially, more unconsciously and now much more consciously, I recognise that there was no possibility of even occupying a third space, as Yuli described it. Therefore, over the time I have been there I have tried to position my identity and the knowledge I bring to my work as a teacher, teacher educator and researcher more as a learner who has expertise in some areas of value to the work I am involved in. This position I could not have articulated on my first visit but it has grown and evolved over time and has been significantly informed by my work as a teacher educator at Oxford where, on our one year Initial Teacher Education Programme, the Oxford Internship Scheme (OIS), we very carefully lay out what expertise the two different partners, the school-based mentors and the Universitybased tutors, bring to the teacher education process. As Hayward (1997) writes:

The roles of the mentor and university tutor are more sharply delineated. The mentor is primarily required to discuss suggestions for practice in the context of their school ... The task of the University tutor is not, primarily to give tips about teaching, however much student teachers say they want these, but to introduce them in a systematic, rigorous and rational way to theoretical arguments about why certain practices, for example, mastery learning, are important and worthy of consideration (pp. 20-21).

This principle of partners in the same endeavour, in this case teacher education, having different and complementary expertise has guided my professional thinking and helped shaped my identity as a teacher educator. I have come to see myself as knowledgeable in some areas which I can share but, more crucially, that I do not have to be expert in every area - this realisation has proved to be professionally very liberating! It also provides an imperative for me that I need to seek out colleagues to collaborate with who have the potential to enrich and complement each other's skills and knowledge in a system of distributed expertise. 


\section{Bhutan's education system}

In this section I want to sketch out some background history about Bhutan, its education system and science education to illustrate the rich complexity of Bhutan's traditions and culture into which I entered in 2007. Bhutan is in the eastern region of the Himalayas situated between China and India. Its mountainous terrain and isolationist policies have served to reduce foreign influence which, it has been argued, has allowed Bhutan to maintain its rich traditional heritage. Bhutan has never been formally colonised and was united as a country by Zhabdrung Ngonwang Namgyel (1594-1651), a Tibetan abbot. The Zhabdrung governed Bhutan as a theocracy where the main purpose of the state was to support the Mahayana Buddhist religious order and to develop a distinctive national identity "guided by driglam namzha (code of behavior or discipline), tsawasum (King; the government and kingdom), tha damtshig (loyalty), and le judre (karmic action retribution, cause and effect)" (Crins 2008, p.81). As Robles (2014) states:

Social relationships and conduct are organized around these values. Moreover, they define what is and is not acceptable in Bhutanese society. Driglam namzha not only sets out rules for 'wholesome' behavior, but also outlines morals, values, and rules for dress .... The traditional style of dress-i.e., the kira for women and gho for men-was instituted during the Zhabdrung's rule and remains the mandatory dress code in government offices, schools, and in most professional settings. (Robles 2014, p.41)

The Zhabdrung and his successors ruled until the founding of the Wangchuk Dynasty and establishment of the hereditary monarchy in 1907. There have been five Kings in Bhutan since 1907. In 2006 the fourth King, HM, Jigme Singye Wangchuck voluntarily abdicated the throne to his son and Bhutan held its first democratic elections in March 2008 and became the world's newest democracy.

Religious education in Bhutan goes back to AD 746 but the system of modern monastic education can be traced to Zhabdrung Ngonwang Namgyel's establishment of Bhutan as a state. As Robles says:

Under the rule of the Zhabdrung, a Central Monk Body was established for the purpose of providing formal education in 'Buddhist philosophy, liturgical chanting, dialectics and linguistics’ (Stiles 2009: 61). (Robles 2014, p. 45)

As said, Bhutan was one of the most isolated countries in the world but the third King Jigme Dorji Wangchuck, who is also known as the Father of Modern Bhutan, instituted changes to begin to modernise Bhutan. Thereafter, Bhutan has always tried to balance modernization with its ancient myths and traditions with Gross National Happiness (GNH) as its guiding philosophy. GNH as a concept was introduced by the fourth King of Bhutan which has the happiness of the people as its guiding goal of development. For example, development in Bhutan is defined in the context of the four pillars of GNH, which include equitable socio-economic development, conservation of culture, conservation of environment and good governance, supplementing each other, not in isolation. Understandably, any developmental activity in Bhutan is screened based on the criterion of four pillars.

Modernisation of education only really began in the late 1950s-1960s and, in 1961, the introduction of the first 5-Year Development Plan increased the number of schools and established a Department of Education under the Ministry of Social Services and then the Ministry of Health and Education. Now there is a nationwide system of modern education from Pre-primary to Class 12 in primary and secondary schools across Bhutan. There are 
now debates in Bhutan, and in the literature, about how Bhutan can maintain its rich cultural traditions and heritage and modernise. This balance has been termed in the literature a 'middle way' or 'middle path' (see, for example, Brunet, Bauer, Lacy and Tshering 2001; Van Willensward 2004). Brunet, Bauer, Lacy and Tshering (2001), for example, in their research on tourism development in Bhutan, found that:

Key stakeholders in Bhutan favour a policy of cautious or 'middle path' modernisation in which the Bhutanese maintain control of the type and amount of tourism and its effect on cultural traditions, religion, and the natural environment. (p. 243)

I will return to the balance between maintaining tradition and modernisation in a later section.

\section{Science education in Bhutan, needs assessment and the development of the curriculum framework}

Bhutan's science education began with a curriculum borrowed from India. However, since this was developed and in 1986 the 'New Approach to Primary Education' (NAPE) was introduced for Classes 4-6 (primary school). This curriculum was particularly designed to be rooted in Bhutan's natural and social environment. In 1999 and 2000, the teaching of science as three subjects, biology, chemistry and physics, in Classes 7 and 8 was replaced by a single integrated science "Science for Class VII: Learning Science through Environment" and "Science for Class VIII: Learning Science through Environment". However, even with these reforms, concerns still existed about the curriculum's fragmentation and lack of a sense of progression (Tenzin and Maxwell 2008).

To address these concerns and to inform the development of science education in Bhutan, UNESCO commissioned an in-depth needs analysis study of science education in Bhutan from all stakeholders' perspectives (teachers, students, parents, employers, universities). This was carried out by myself and two colleagues at OUDE in collaboration with colleagues from the CAPSD. The key colleague that we worked with was from CAPSD was Mr Wangpo Tenzin. The process and analysis of this needs assessment has been published as Childs, Tenzin, Johnson and Ramachandran (2012).

Arriving in Bhutan I was astonished by its beauty and, in meeting the colleagues we were collaborating with, I felt little culture shock in the negative ways described in their paper and compared with the severe culture shock I had experienced in Sierra Leone. I think this was partly because I was only going to be there for 3 weeks, my time in Sierra Leone was 3 years, and partly because all colleagues in CAPSD, the Ministry of Education and the teachers we met all spoke excellent English. On reflection, I have now realised how being able to communicate and to be understood is integral to my professional identity and how my initial lack of ability to communicate had contributed significantly to the erosion of my professional identity in the early stages of working in Sierra Leone.

In reflecting on this work for this paper I also realised that the way we designed and worked on the needs assessment drew on the distinctive expertise of the two partners from the OUDE and CAPSD. From my perspective it was evident that in the 3 weeks I was in Bhutan there was little chance I could understand the complexity of the context and culture in any meaningful way. In our early meetings with $\mathrm{Mr}$ Tenzin he expressed the wish to learn from us about how to design a robust study that would seek the views of the key stakeholders in Bhutan about the issues and challenges of the current science curriculum. Over time it has become evident to me that Mr Tenzin offered us a cultural bridge and access to the key stakeholders whose views were vital to the success of the needs 
assessment. He knew, for example, that it was crucial politically that we visit all Dzongkhags (districts) in Bhutan and all types of school. Thus, rather unconsciously at this stage, it seems that each party did indeed bring their distinctive and complementary expertise to the process. In the study we travelled across Bhutan and Mr Tenzin organised our access to schools, teachers and pupils. When we arrived at the schools his intimate knowledge of the schools meant we met with head teachers and then had long focus group meetings with teachers to get their views on the strengths and weakness of their curriculum. We also spoke with pupils and observed lessons. It was our job to design the questions (mostly very open) and, at the end of the process, to analyse the data and to work in collaboration with Mr Tenzin to write the final report. He also joint authored the article we published in the International Journal of Science Education (Childs, Tenzin, Johnson and Ramachandran 2012). One unintended and significant outcome of the decision by $\mathrm{Mr}$ Tenzin that we needed to visit schools as far east as Trashigang was that we spent many long hours in the car; it is a three day drive to Trashigang and we stopped off and visited schools in Wangdue Phodrang and Trongsa. We used this time to discuss our developing ideas coming from the interviews with teachers and also, more significantly, we learned more about Bhutan and science education from Mr Tenzin. On reflection this formed an integral and incredibly valuable part of the process and allowed for an understanding, superficial though it still was, of some cultural knowledge of Bhutan and, as collaborators, we all got to know each other better.

After the report was published I was invited to work with Mr Tenzin in the process of reshaping the science curriculum to address the issues raised in the needs assessment. We held two-three day workshops in Paro, Thimpu and Wangdue Phodrang with science teachers (primary and secondary) and other key stakeholders (e.g. higher education lecturers and key employers) - 137 participants in all. Again, Mr Tenzin organised the four workshops and I facilitated and jointly planned the workshops with him and, again, our expertise complemented each other. In both the needs assessment and in these workshops, another layer of expertise was added into the equation: that of the teachers and key stakeholders. They brought to bear their knowledge of Bhutan's learners and their knowledge of the country's culture, myths and traditions in order to shape a science curriculum framework that would be appropriate for Bhutan's learners.

Many debates and issues arose in these meetings as the teachers and key stakeholders shaped the curriculum, too many to report on in this short paper. But I want to pick on one below that demonstrated the importance of drawing on the cultural expertise of the teachers and stakeholders and why, I, as an outsider in this context, had always to position myself more as a facilitator. There was no possibility in my short exposure to Bhutan and its rich culture and traditions that I could enter these discussions in any more direct way. In the workshops the same debates arose about the relationship between a 'modern' science curriculum and Bhutan's rich culture and traditions. The views on this essentially fell into four groups:

1. Those who were comfortable that science should challenge traditional myths and beliefs that conflicted with current scientific understandings

2. Those who were concerned that science was being set against traditional myths and beliefs and that science should not undermine the country's cultural traditions

3. Those who argued that many of the myths and traditional beliefs were compatible with scientific understandings and that the two should not been seen as in conflict 
4. Those who felt that science and the myths and traditions were different ways of knowing and addressed different kinds of questions and therefore should not be brought together.

What we seemed to be seeing being played out in the discussions were debates about how to reconcile a modern science curriculum with Bhutan-rich traditions and myths and how, in many ways, the development of the curriculum framework could tread the 'middle path' described above. In all the workshops no consensus between these different positions was reached, each of the views expressed was defended passionately and with great conviction. For example, in the workshop in Thimpu the participant from geology and mines told a traditional story about a forest, the details of which I have forgotten, but it illustrated a traditional story about how myths and traditional beliefs of Bhutan were compatible with scientific understandings. This input resonates with the literature on science education. Overson Shumba (1999), for example, in talking about traditional and cultural beliefs of science teachers in Zimbabwe, says that:

It therefore seems essential that an important goal of science education in a developing non-western country such as Zimbabwe ought to be an understanding and critical interrogation of Western science relative to locally held worldviews. As Nagel (1992) intimated it is crucial for cultural issues to be included in the curriculum and be subjected to critical discourse with the hope, in the case of science education, that science and tradition can be brought into conflation. (p. 352)

However, others argued just as passionately that myths and traditions could be harmful to Bhutan's learners and this view also resonates with science education literature. For example, Keith Lewin (1992), in summarising research on the issue of culture particularly in the African context, identifies a number of issues and challenges including "the difficulties of bringing Western science to African children whose traditional background places emphasis on myth and superstition, and encourages unquestioning belief in statements of people in authority" (p. 130). Lewin seems to be arguing that myth and tradition may hinder children's understanding of science where they are not consistent with current scientific understanding. The issues raised by the participants in our workshops are therefore not unknown in science education and are complex issues and challenging to resolve. This is particularly so in the Bhutan context as myth and tradition are an important part of Bhutanese culture, enshrined in the dimensions of GNH.

To resolve the lack of agreement Mr Tenzin and I spent considerable time discussing how we could reflect this diversity of views; in the end, as in other curricula worldwide and similar with the view expressed above in (iv) we included statements that reflected that science and religion are different ways of knowing and address different kinds of questions. However, as we acknowledged at the time, this only represented a partial solution and felt to me somewhat of a fragile compromise. Indeed, at the same time as we were having challenges in getting consensus as to what might constitute an acceptable 'middle path', Robles (2014) was describing the actual pedagogical challenges that science teachers were experiencing in trying to mediate tensions between science and Bhutan's traditional beliefs and myths. In her research she identified a range of pedagogic strategies teachers were employing in the realities of science classrooms to navigate a 'middle path' and these were:

- Accommodating beliefs and myths into everyday science classrooms

- Inviting discussion of traditional beliefs and myths in science classrooms

- Subordinating traditional beliefs and myths privileging western science understandings 
- Dismissing and avoiding traditional beliefs and myths in science classrooms.

In all of the debates surfacing in the workshops I felt my role was to listen and try and reflect back the arguments being presented. However, Mr Tenzin and I had to, as described above, make the decision about how one particular set of debates would be resolved in the final curriculum framework and, as indicated, this resulted in compromise. Mr Tenzin in his work at CAPSD was then responsible for developing the support materials for the new curriculum framework (teachers' guides and textbooks). He brought to this his expertise and knowledge of Bhutan; indeed he has played a key part in workshops in Bhutan developing ideas about GNH. He is very aware of the debates around modernisation and tradition in Bhutan and so was the right person to take the framework forward. All the discussions in the workshops culminated in the production of the Science Curriculum Framework for classes Pre-Primary to twelve for Bhutan, which encapsulated wider world views of science grounded in GNH and which guided the curriculum developers to develop science textbooks suitable for twenty-first century learners in Bhutan.

After 2011, CAPSD, now known as the Department of Curriculum Research and Development (DCRD) started the development of series of science textbooks and teachers' manuals for classes four to twelve. Based on the experience gained through the collaboration with the OUDE team and the CAPSD, Mr Tenzin, serving as the curriculum specialist and Dean for the Curriculum Development Centre under the Royal Education Council, faciltiated the development of curriculum materials for all school subjects in Bhutan. For example curriculum frameworks and activity guides for subjects such as Health and Physical Education, Values Education, Accountancy, Geography, History, Environmental Science and Social Studies were either revised or developed and implemented.

\section{Postscript and conclusion}

The development of the curriculum framework, in collaboration with Mr Tenzin and all the teachers and stakeholders in the needs assessment and curriculum development process, was a fascinating and fruitful experience in which I learned much. As far as I could I adhered as closely as possible to staying within the bounds of the expertise I felt I could contribute. My experience of living and working in Sierra Leone had demonstrated that, even after 3 years, my 'cultural knowledge' was still fragile and so the very short periods I was spending in Bhutan meant I had to think very carefully about the path that I trod. I was privileged in working with Mr Tenzin and all the teachers and stakeholders that allowed their deep understanding of Bhutan, its cultures and traditions and its learners to be shared and significantly inform the curriculum development process. It would be wrong to say that I didn't offer my views or indeed significantly shape the process myself and, of course, this happened. The example above is but one example; there were many more.

However, these experiences more recently informed some work I am continuing to do in Bhutan. I have been involved for 3 years in working with colleagues from Bhutan and India in supporting teacher development for the Royal Academy. This is an institution set up by the fifth King his Royal Highness King Khesar Namgyel Wangchuck which:

aspires to stand out as a centre of excellence-one where education is a dialectical process that enables collaboration amongst learners, teachers, teacher-educators, and researchers. The Academy's commitment to on-going research on education, curriculum, and teacher development will be achieved through the establishment of a 
unique triad model consisting of three interlinked centres: the School, the Education Research Centre, and the Teacher Development Centre. (The Royal Academy n.d., p. 3)

The school, as one of the centres of the Royal Academy, has been running for over a year and in my recent visit with a colleague from OUDE we were asked to support teachers in bringing more research-informed perspectives to their professional development and, in particular, to consider action research either conducted individually or in groups as a possible way forward. Our expertise in this area was to share our knowledge about how action research works and its potential to facilitate teacher learning and development. We then worked with individuals and groups of teachers as they shaped their individual, department and school action research projects, rooted in their expert knowledge of the Academy's learners and its aims and philosophy. My colleague and I recognised that any action research projects developed had to be in the hands of the teachers as they understood their context intimately. In the end the teachers developed a wide range of individual and group projects ranging from: individual action research projects on the impact of playing a range of indigenous games on the fitness, motivation and cultural understanding of academy learners; learning how to learn Dzongkha skills (spelling, vocabulary and basic sentence structure); and being mindful inside the classrooms; to a group project on bringing the rich resources of the Bhutan environment into the classroom and curriculum. We hope to continue to work with the teachers as these projects are carried out.

Finally, in my professional and academic life the balance between what I feel I can genuinely contribute expertise to in situations where the cultural milieu is different, and in this I include the local schools in Oxford that we work in on the OIS, has been a constant challenge through my professional career. I cannot pretend that in my experience of teaching and living in Sierra Leone I reflected very deeply on my identity. In many ways the post hoc reflection this article has required has made me understand the journey I have been on and hopefully has allowed me to make a slightly more honest analysis of my own identity, my professional and personal expertise and the limits of this. Sierra Leone taught me that even in 3 years of constantly living and working with colleagues I still had a lot to learn. But what I have also realised is that the process of working in collaboration with colleagues whose expertise, when blended with mine, has made the whole of what we have tried to do a much richer enterprise than the sum of its parts. As a fish swimming in waters of unfamiliarity every day, swimming with the shoal is definitely my preferred way forward. In all of my work with colleagues in Sierra Leone, Oxford and Bhutan, they have generously helped me navigate new challenges, enough, I hope, for me to have had at least a chance of offering something of value.

Open Access This article is distributed under the terms of the Creative Commons Attribution 4.0 International License (http://creativecommons.org/licenses/by/4.0/), which permits unrestricted use, distribution, and reproduction in any medium, provided you give appropriate credit to the original author(s) and the source, provide a link to the Creative Commons license, and indicate if changes were made.

\section{References}

Brunet, S., Bauer, J., Lacy, T., \& Tshering, K. (2001). Tourism development in Bhutan: Tensions between tradition and modernity. Journal of Sustainable Tourism, 9(3), 243-263. doi:10.1080/ 09669580108667401. 
Childs, A., Tenzin, W., Johnson, D., \& Ramachandran, K. (2012). Science education in Bhutan: Issues and challenges. International Journal of Science Education, 34(3), 375-400. doi:10.1080/09500693.2011. 626461.

Crins, R. (2008). Meeting the other: Living in the present, gender and sustainability in Bhutan. Delft: Uitgeverj Eburon.

Hayward, G. (1997). Principles for school focused initial teacher education: Some lessons from the Oxford Internship Scheme. In T. Allsop \& A. Benson (Eds.), Mentoring for science teachers (pp. 11-26). Buckingham: Oxford University Press.

Lewin, K. M. (1992). Science education in developing countries; issues and perspectives for planners. Paris: Research and Studies, International Institute for Educational Planning, UNESCO.

Nagel, T. (1992). Quality between tradition and modernity: Patterns of communication and cognition in teacher education in Zimbabwe. Oslo: University of Oslo.

Rahamawati, Y., \& Taylor, P. C. (this issue). The fish becomes aware of the water in which it swims: Revealing the power of culture in shaping my teaching identity. Cultural Studies of Science Education. doi:10.1007/s11422-016-9801-1.

Robles, C. (2014). Tradition, modernisation, and education reform in Bhutan: Irreducible tension? Ph.D. University of Oxford.

Shumba, O. (1999). Relationship between secondary science teachers' orientation to traditional culture and beliefs concerning science instructional ideology. Journal of Research in Science Teaching, 36(3), 333-355. doi:10.1002/(SICI)1098-2736(199903)36:3<333:AID-TEA7>3.0.CO;2-Z.

Stiles, K. (2009). Navigating learning in Bhutan, land of the thunder dragon (Doctoral disseration). Retrieved from ProQuest Dissertations and Theses database. (UMI No. 3371687).

Tenzin, W., \& Maxwell, T. (2008). Primary science education in Bhutan. In N. Tyler \& I. Mike (Eds.), Science education in context (pp. 313-332). Taiwan: Sense Publication.

The Royal Academy (n.d). Thimphu, Bhutan: Royal Academy Project Office His Majesty's Secretariat.

Van Willensward, H. (2004). Will 'middle way economics' emerge from the gross national happiness approach of Bhutan? In K. Ura \& K. Galay (Eds.), Gross national happiness and development, proceedings of the first international seminar on operationalization of gross national happiness (pp. 214-221). Thimpu: The Centre for Bhutan Studies.

Ann Childs has a B.Sc. (hons) and Ph.D. in organofluorine chemistry from Birmingham University. She gained a Postgraduate Certificate in Education (PGCE) from the Department of Educational Studies at Oxford University in 1984 and then worked as a science teacher for 11 years, three years in Sierra Leone. She has been an Associate Professor in Science Education at The Department of Education at Oxford University since 1997. Her main teaching role is as a teacher educator of secondary science teachers and her current key research interest is the professional development of science teachers and science teacher educators. She has worked in the area of science education in a number of countries for example, Kenya, Uganda, Pakistan and Bhutan. 